\title{
Physiological differences between twin and single-born lambs and kids during the first month of life
}

\author{
Francesco Fazio $^{1}$, Francesca Arfuso ${ }^{1}$, Elisabetta Giudice ${ }^{2}$, Claudia Giannetto ${ }^{1}$, and Giuseppe Piccione ${ }^{1}$ \\ ${ }^{1}$ Department of Veterinary Sciences, Polo Universitario Annunziata, University of Messina, \\ 98168 Messina, Italy \\ ${ }^{2}$ Department of Chemical, Biological, Pharmaceutical and Environmental Sciences, \\ University of Messina, Viale Ferdinando Stagno d'Alcontres 31, 98166 Sant'Agata, Messina, Italy \\ Correspondence to: Francesco Fazio (francesco.fazio@unime.it)
}

Received: 2 March 2016 - Revised: 18 April 2016 - Accepted: 28 April 2016 - Published: 4 May 2016

\begin{abstract}
The effects of time after birth and of twinning on rectal temperature (RT), heart rate (HR), respiratory rate (RR) and body weight (BW) values were evaluated in five singleton Comisana lambs (three males and two females), five singleton Maltese Kids (three males and two females), four couples of twin Comisana lambs (four males and four females) and four couples of twin Maltese kids (four males and four females) during the first month of life. For all kids and lambs, RT, HR, RR and BW were recorded after 1 and $24 \mathrm{~h}$ from birth and every 2 days until the 30th day of life. The application of two-way repeated measures analysis of variance (ANOVA) showed a statistically significant effect of time $(P<0.0001)$ on RT, HR, RR and BW values in all lambs and kids during the first month of life. Any significant effect of twinning $(P>0.05)$ on all studied parameters was found in lambs, whereas statistically significant differences in BW, RT and HR values $(P<0.01)$ were found between twin and singleton kids throughout the first month of life. The results obtained in this study make a contribution to the knowledge of homeostatic, cardiorespiratory and thermoregulatory adaptations occurring in singleton lambs and kids and in twin lambs and kids during the first 30 days of life. Our findings indicate that the BW, RT, HR and RR values, whose homeostasis is still evolving in newborn, should be interpreted dynamically as a function of the period of postnatal adaptation and also of twinning.
\end{abstract}

\section{Introduction}

The management of newborn livestock species from birth until weaning has an impact on herd productivity, and the economic return will depend on the survival of the offspring. Physiological immaturity is considered the major determinant of mortality and morbidity in newborn resulting in economic losses in livestock production (Dwyer et al., 2005; Stafford et al., 2007; Piccione et al., 2008, 2009, 2010). A substantial proportion of postnatal diseases or death could be prevented by good management and by early intervention and by diagnosis and treatment of situations that involve a high-risk newborn. The postnatal period, known as the adaptative period, is a critical life stage that begins at birth and extends until the 30th day of life and that reflects the ability of newborn to complete their maturation with the animal's adaptation to extrauterine life (Piccione et al., 2007; Vannucchi et al., 2012). At birth and during the subsequent days of extrauterine life, the thermoregulatory, cardiovascular, respiratory and homeostatic mechanisms complete newborn maturation (Chniter et al., 2013).

Studies carried out on newborn calves, lambs and kids demonstrated that the respiratory, cardiovascular and thermoregulatory function of these livestock species is subjected to several adjustments following the transition from the controlled uterine environment to the free-living state (Nowak and Poindron, 2006; Al-Tamimi, 2007; Ocak et al., 2009; Piccione et al., 2010, 2013; Davey et al., 1998). These physiological functions are also influenced by the birth weight of the animal (De Matteo et al., 2008; Chniter et al., 2013), which in turn depends on fetal physiological adaptations made in response to the intrauterine conditions (De Matteo 
et al., 2008). In this regard, multiple gestation is recognized as a natural cause of intrauterine growth restriction leading to a decrease in birth weight of twin births compared to singleton births (de Geus et al., 2001). Although many authors have studied the differences in several physiological functions between singleton and twin offspring in human, ovine and caprine species, conflicting results were obtained (Poulter et al., 1999; Baird et al., 2001; Aleksiev, 2009). Several studies showed that triplet-born lambs have lighter birth weights, a lower body temperature and some lower plasma parameter levels than twin-born lambs, resulting in a poor thermoregulatory function during the postnatal period (Morris and Kenyon, 2004; Stafford et al., 2007). Studies comparing blood pressure or heart rate (HR) in singletons and twins have shown either no effect (de Geus et al., 2001), higher values in twins (Dwyer et al., 1999) or lower values in twin (De Matteo et al., 2008). These discordant results are likely due to uncontrolled factors between groups, including dam or offspring nutrition and a lack of differentiation between monozygotic and dizygotic twins (De Matteo et al., 2008).

Because of the importance of deepening the knowledge on adaptation processes occurring during the postnatal period in order to improve management techniques and to prevent postnatal diseases or death, this study aimed to evaluate the effect of time after birth and of twinning on rectal temperature, heart rate, respiratory rate and body weight in lambs and kids during the first month of life.

\section{Material and methods}

\subsection{Animals}

This study was carried out on five singleton (three males and two females) and eight twin (four males and four females) Comisana lambs, on the one hand, and five singleton (three males and two females) and eight twin Maltese kids (four males and four females), on the other hand, born from multiparous Comisana sheep and Maltese goats, respectively, on the same farm, situated in northeast Sicily $\left(37^{\circ} 43^{\prime} 24^{\prime \prime} \mathrm{N}\right.$, $13^{\circ} 26^{\prime} 05^{\prime \prime} \mathrm{E}$; $966 \mathrm{~m}$ above sea level).

All dams, aged 4-5 years old, were fed with a constant diet composed of a concentrate mixture which consisted of the following ingredients: oats (12\%), faba bean (15\%), barley $(25 \%)$, pea $(10 \%)$, sugar beet pulp $(20 \%)$, molasses $(5 \%)$, and mineral and vitamins supplements (3\%). Foragebased diets were alfalfa (Medicago sativa L.) hay. About $250 \mathrm{~g} \mathrm{animal}^{-1}$ of concentrate was distributed twice a day and water was available ad libitum. Every day the dams were herded out and grazed on an improved natural pasture from 10:00 to 18:00 LT.

All lambs and kids were born at term in spring (sunrise: 05:15; sunset: 21:02) at similar gestational age (singleton lamb: $148 \pm 1$ days; twin lambs: $146 \pm 1$ days; singleton kids: $152 \pm 2$ days; twin kids: $153 \pm 1$ days). They were kept in boxes with their dam in order to guarantee ad- equate mothering and to minimize disruption. Thermal and hygrometric measurements were carried out inside the box for the whole study by means of a data logger (Gemini, UK), and they agreed with the normal seasonal pattern for the location (minimum and maximum temperature between 13.6 and $22.8^{\circ} \mathrm{C}$, mean relative humidity of $57 \%$ ). The newborn lambs and kids were considered clinically healthy. Their health status was evaluated at birth based on behavior, rectal temperature, heart and respiratory profile, cough, nasal discharge, ocular discharge, appetite, faecal consistency, navel examination, and haematological profile (data not shown). Lambs and kids were fed only with colostrum and maternal milk. Each day the lambs and kids were herded out and grazed on an improved natural pasture with their dams. At pasture they suckled freely.

\subsection{Data collection}

Once the lambs and kids were born, their birth data, type of birth and sex were recorded and they were allowed to suckle successfully unaided.

For all lambs and kids, rectal temperature (RT), HR, respiratory rate (RR) and body weight $(\mathrm{BW})$ were recorded by the same operator after $1\left(T_{0}\right)$ and $24\left(T_{1}\right) \mathrm{h}$ from birth and every 2 days until the 30 th day of life $\left(T_{2}, T_{4}, T_{6}, T_{8}, T_{10}, T_{12}, T_{14}\right.$, $T_{16}, T_{18}, T_{20}, T_{22}, T_{24}, T_{26}, T_{28}$ and $\left.T_{30}\right)$.

The RT was recorded using a digital thermometer (model HI92704, Hanna Instruments, Bedfordshire, UK) with the probe being inserted to a depth of $4 \mathrm{~cm}$. The HR was measured by means of an oscillometric apparatus (Argus TM-7; Schiller, Barr, Switzerland). The RR was assessed visually by observation of chest and abdomen movements and auscultation with a stethoscope over a 5 min period. The BW was measured by a means of a weighing platform (PS1000 Livestock Scale, Brecknell, UK).

In our study, protocols of animal husbandry and experimentation were reviewed and approved in accordance with the standards recommended by the Guide for the Care and Use of Laboratory Animals and Directive 2010/63/EU for animal experiments.

\subsection{Statistical analysis}

All data were tested for normality of distribution using the Kolmogorov-Smirnov test. All data were normally distributed $(P>0.05)$, and statistical analysis was performed. Two-way repeated measures analysis of variance (ANOVA) was applied to assess the statistically significant effect of time (days of life) and of twinning on BW, RT, HR and RR values measured in lambs and kids during the first month of life. Duncan's multiple comparison test was applied for post hoc comparison. $P$ values $<0.05$ were considered statistically significant. 
Table 1. Mean \pm standard deviation of body weight (BW), rectal temperature (TR), respiratory rate (RR) and heart rate (HR) values measured in twin and singleton lambs at each time point $\left(T_{0}-T_{30}\right)$ of experimental period.

\begin{tabular}{|c|c|c|c|c|c|c|c|c|}
\hline \multirow[t]{2}{*}{ Time } & \multicolumn{2}{|c|}{$\mathrm{BW}(\mathrm{kg})$} & \multicolumn{2}{|c|}{$\operatorname{TR}\left({ }^{\circ} \mathrm{C}\right)$} & \multicolumn{2}{|c|}{$\mathrm{RR}$ (breaths $\min ^{-1}$ ) } & \multicolumn{2}{|c|}{ HR (beats $\min ^{-1}$ ) } \\
\hline & $\begin{array}{c}\text { Twin } \\
(n=8)\end{array}$ & $\begin{array}{c}\text { Singleton } \\
(n=5)\end{array}$ & $\begin{array}{c}\text { Twin } \\
(n=8)\end{array}$ & $\begin{array}{c}\text { Singleton } \\
(n=5)\end{array}$ & $\begin{array}{c}\text { Twin } \\
(n=8)\end{array}$ & $\begin{array}{c}\text { Singleton } \\
(n=5)\end{array}$ & $\begin{array}{c}\text { Twin } \\
(n=8)\end{array}$ & $\begin{array}{c}\text { Singleton } \\
(n=5)\end{array}$ \\
\hline$T_{0}$ & $4.12 \pm 0.18^{\mathrm{a}}$ & $4.49 \pm 0.45^{\mathrm{a}}$ & $39.8 \pm 0.1^{\mathrm{c}}$ & $39.8 \pm 0.2^{\mathrm{c}}$ & $91 \pm 1^{1}$ & $91 \pm 1^{p}$ & $189 \pm 3^{\mathrm{a}}$ & $184 \pm 4^{\mathrm{a}}$ \\
\hline$T_{1}$ & $4.23 \pm 0.19^{\mathrm{a}}$ & $4.61 \pm 0.45^{\mathrm{a}}$ & $39.7 \pm 0.1^{\mathrm{i}}$ & $39.7 \pm 0.1^{\mathrm{c}}$ & $89 \pm 1^{b}$ & $91 \pm 2^{p}$ & $183 \pm 2^{\mathrm{a}}$ & $178 \pm 2^{b}$ \\
\hline$T_{2}$ & $4.35 \pm 0.20^{\mathrm{a}}$ & $4.72 \pm 0.45^{\mathrm{a}}$ & $39.7 \pm 0.1^{\mathrm{d}}$ & $39.7 \pm 0.2^{\mathrm{c}}$ & $87 \pm 1^{\mathrm{m}}$ & $90 \pm 1^{\mathrm{m}}$ & $178 \pm 2^{b}$ & $178 \pm 3^{b}$ \\
\hline$T_{4}$ & $4.59 \pm 0.22^{\mathrm{a}}$ & $4.96 \pm 0.45^{\mathrm{a}}$ & $39.7 \pm 0.1^{\mathrm{d}}$ & $39.7 \pm 0.2$ & $86 \pm 1^{\mathrm{e}}$ & $88 \pm 1^{\mathrm{c}}$ & $176 \pm 4^{c}$ & $176 \pm 4^{\mathrm{c}}$ \\
\hline$T_{6}$ & $4.82 \pm 0.25^{\mathrm{a}}$ & $5.19 \pm 0.45^{\mathrm{a}}$ & $39.7 \pm 0.1^{\mathrm{d}}$ & $39.7 \pm 0.2^{\mathrm{e}, \mathrm{t}, \mathrm{u}}$ & $85 \pm 1^{\mathrm{i}}$ & $88 \pm 2^{\mathrm{c}}$ & $174 \pm 6^{\mathrm{c}}$ & $174 \pm 3^{\mathrm{i}}$ \\
\hline$T_{8}$ & $5.06 \pm 0.27^{\mathrm{a}}$ & $5.42 \pm 0.45^{\mathrm{a}}$ & $39.7 \pm 0.1^{\mathrm{d}}$ & $39.7 \pm 0.1^{\mathrm{e}}$ & $84 \pm 2^{\mathrm{i}}$ & $85 \pm 3^{\mathrm{i}}$ & $173 \pm 4^{c}$ & $173 \pm 4^{\mathrm{i}}$ \\
\hline$T_{10}$ & $5.29 \pm 0.29^{\mathrm{a}}$ & $5.65 \pm 0.44^{\mathrm{a}}$ & $39.6 \pm 0.1^{\mathrm{e}}$ & $39.6 \pm 0.2^{\mathrm{h}}$ & $83 \pm 2^{\mathrm{d}}$ & $84 \pm 2^{\mathrm{d}}$ & $169 \pm 4^{c}$ & $172 \pm 4^{\mathrm{i}}$ \\
\hline$T_{12}$ & $5.52 \pm 0.31^{\mathrm{a}}$ & $5.88 \pm 0.44^{\mathrm{a}}$ & $39.6 \pm 0.1^{\mathrm{g}}$ & $39.6 \pm 0.2^{\mathrm{g}}$ & $81 \pm 1^{\mathrm{d}}$ & $82 \pm 3^{n}$ & $166 \pm 3^{d}$ & $168 \pm 2^{\mathrm{e}}$ \\
\hline$T_{14}$ & $5.76 \pm 0.34^{\mathrm{a}}$ & $6.11 \pm 0.44^{\mathrm{a}}$ & $39.5 \pm 0.1^{\mathrm{o}}$ & $39.6 \pm 0.2^{\mathrm{h}}$ & $79 \pm 2^{\mathrm{n}}$ & $80 \pm 3^{n}$ & $164 \pm 4^{e}$ & $166 \pm 4^{\mathrm{f}}$ \\
\hline$T_{16}$ & $5.99 \pm 0.36^{\mathrm{a}}$ & $6.35 \pm 0.44^{\mathrm{a}}$ & $39.6 \pm 0.1^{\mathrm{o}}$ & $39.6 \pm 0.2^{\mathrm{g}}$ & $76 \pm 2^{f}$ & $77 \pm 2^{f}$ & $163 \pm 3^{f}$ & $166 \pm 5^{\mathrm{f}}$ \\
\hline$T_{18}$ & $6.22 \pm 0.38^{\mathrm{a}}$ & $6.58 \pm 0.44^{\mathrm{a}}$ & $39.5 \pm 0.1^{\mathrm{j}}$ & $39.5 \pm 0.1^{\mathrm{h}}$ & $76 \pm 3^{f}$ & $75 \pm 2^{\mathrm{g}}$ & $160 \pm 3^{\mathrm{g}}$ & $163 \pm 2^{\mathrm{g}}$ \\
\hline$T_{20}$ & $6.46 \pm 0.41^{\mathrm{a}}$ & $6.81 \pm 0.43^{\mathrm{a}}$ & $39.5 \pm 0.1^{\mathrm{j}}$ & $39.5 \pm 0.1^{\mathrm{h}}$ & $73 \pm 3^{h}$ & $73 \pm 3^{\mathrm{h}}$ & $160 \pm 3^{h}$ & $161 \pm 4^{\mathrm{g}}$ \\
\hline$T_{22}$ & $6.70 \pm 0.43^{\mathrm{a}}$ & $7.04 \pm 0.43^{\mathrm{a}}$ & $39.4 \pm 0.1^{\mathrm{j}}$ & $39.4 \pm 0.1^{\mathrm{j}}$ & $71 \pm 2^{\circ}$ & $71 \pm 2^{0}$ & $158 \pm 3^{\mathrm{h}}$ & $157 \pm 4^{j}$ \\
\hline$T_{24}$ & $6.93 \pm 0.45^{\mathrm{a}}$ & $7.27 \pm 0.43^{\mathrm{a}}$ & $39.4 \pm 0.1^{q}$ & $39.4 \pm 0.1^{\mathrm{j}}$ & $70 \pm 3^{j}$ & $69 \pm 2^{0}$ & $154 \pm 3^{\mathrm{h}}$ & $156 \pm 4^{j}$ \\
\hline$T_{26}$ & $7.17 \pm 0.47^{\mathrm{a}}$ & $7.50 \pm 0.43^{\mathrm{a}}$ & $39.4 \pm 0.1$ & $39.3 \pm 0.1^{\mathrm{k}}$ & $67 \pm 3^{\mathrm{k}}$ & $66 \pm 2^{j}$ & $152 \pm 3$ & $154 \pm 5^{\mathrm{k}}$ \\
\hline$T_{28}$ & $7.40 \pm 0.50^{\mathrm{a}}$ & $7.74 \pm 0.43^{\mathrm{a}}$ & $39.3 \pm 0.1$ & $39.2 \pm 0.1$ & $66 \pm 6^{\mathrm{k}}$ & $63 \pm 2^{\mathrm{k}}$ & $152 \pm 3$ & $152 \pm 3$ \\
\hline$T_{30}$ & $7.64 \pm 0.52^{\mathrm{a}}$ & $7.97 \pm 0.42^{\mathrm{a}}$ & $39.3 \pm 0.1$ & $39.1 \pm 0.1$ & $63 \pm 3$ & $59 \pm 3$ & $152 \pm 3$ & $150 \pm 2$ \\
\hline
\end{tabular}

Significance of the effect of $(P<0.0001):{ }^{\text {a }}$ vs. $T_{1}-T_{30} ;{ }^{\mathrm{b}}$ vs. $T_{6}-T_{30} ;{ }^{\mathrm{c}}$ vs. $T_{10}-T_{30} ;{ }^{\mathrm{d}}$ vs. $T_{14}-T_{30} ;{ }^{\mathrm{e}}$ vs. $T_{18}-T_{30} ;{ }^{\mathrm{f}}$ vs. $T_{20}-T_{30} ;{ }^{\mathrm{g}}$ vs. $T_{22}-T_{30} ;{ }^{\mathrm{h}}$ vs. $T_{24}-T_{30} ;{ }^{\mathrm{i}}$ vs. $T_{12}-T_{30} ;{ }^{\mathrm{j}}$ vs. $T_{28}-T_{30} ;{ }^{\mathrm{k}}$ vs. $T_{30} ;{ }^{\mathrm{l}}$ vs. $T_{2}-T_{30} ;{ }^{\mathrm{m}}$ vs. $T_{8}-T_{30} ;{ }^{\mathrm{n}}$ vs. $T_{16}-T_{30} ;{ }^{\mathrm{o}}$ vs. $T_{26}-T_{30} ;{ }^{\mathrm{p}}$ vs. $T_{4}-T_{30} ;{ }^{\mathrm{q}}$ vs. $T_{28} ;{ }^{\mathrm{r}}$ vs. $T_{10} ;{ }^{\mathrm{s}}$ vs. $T_{14}$.

Statistical analysis was performed using the STATISTICA software package (STATISTICA 7 Stat Software Inc., Tulsa, Oklahoma, USA).

\section{Results and discussion}

All the results were expressed as means \pm standard deviation $(\mathrm{M} \pm \mathrm{SD})$.

The application of two-way ANOVA showed a statistically significant effect of time $(P<0.0001)$ on $\mathrm{BW}, \mathrm{RT}$, HR and $R R$ values measured in both singleton and twin lambs and in both singleton and twin kids during the first month of life. In particular, all lambs and kids showed a statistically significant increase in BW values $(P<0.0001)$ from birth until the end of the monitoring period and a statistically significant decrease in RT, HR and RR values $(P<0.0001)$ from birth until the end of the monitoring period (Tables 1 and 2). These changes reflect the physiological adjustments likely to occur in a newborn animal following transition from the controlled uterine environment to the free-living state. It has been stated that ovine and caprine newborns have high metabolic rates immediately after the birth, which may increase their body temperatures at this time (Vannucchi et al., 2012). The decrease in the RT values observed $24 \mathrm{~h}$ after birth may be due to a reduction in heat generation for body temperature maintenance. The observed RT fluctuations may indicate either that the thermoregulatory set point was not specified yet by the central nervous system or that the thermoregulatory mechanisms were not mature enough to maintain RT values within the already fixed set point (Aleksiev, 2009). The subsequent decrease in the RT values found in lambs and kids until day 30 of life may be related to the withdrawal of the placental inhibitors from the circulation and the initiation of nonshivering thermogenesis in brown adipose tissue (Aleksiev, 2009; Plush et al., 2016). Similar patterns of RT dynamics were established in a previous study on newborn lambs and kids during the first day after delivery (Aleksiev, 2009). This similarity in RT behavior in the newborn of the two species strongly supports the concept of genetic control of the homeothermy development in newborn (Aleksiev, 2009; Plush et al., 2015). The HR and RR in all lambs and kids observed in this study showed higher values with respect to the reported range in adult sheep and goats (Hemingway and Hemingway, 1966; Miller and West, 1972). It has been stated that younger animals have higher heart rates (Mir et al., 2000) and, owing to a higher surface area, also have higher respiration rates (Mir et al., 2000). Decreases in $\mathrm{HR}$ and RR values were found in both species throughout the monitoring period. These changes highlighted the morphofunctional modifications of the cardiovascular and respiratory system, leading the organism to adapt to the extrauterine environment with a well-defined homeostatic ability (Piccione et al., 2007). The heart is forced to pump the blood through a vascular system that presents strong elastic, periph- 
Table 2. Mean \pm standard deviation of body weight (BW), rectal temperature (TR), respiratory rate (RR) and heart rate (HR) values measured in twin and singleton kids at each time points $\left(T_{0}-T_{30}\right)$ of experimental period.

\begin{tabular}{|c|c|c|c|c|c|c|c|c|}
\hline \multirow[t]{2}{*}{ Time } & \multicolumn{2}{|c|}{$\mathrm{BW}(\mathrm{kg})$} & \multicolumn{2}{|c|}{$\operatorname{TR}\left({ }^{\circ} \mathrm{C}\right)$} & \multicolumn{2}{|c|}{$\mathrm{RR}$ (breaths $\min ^{-1}$ ) } & \multicolumn{2}{|c|}{ HR (beats $\min ^{-1}$ ) } \\
\hline & $\begin{array}{l}\text { Twin } \\
(n=8)\end{array}$ & $\begin{array}{l}\text { Singleton } \\
(n=5)\end{array}$ & $\begin{array}{c}\text { Twin } \\
(n=8)\end{array}$ & $\begin{array}{l}\text { Singleton } \\
(n=5)\end{array}$ & $\begin{array}{l}\text { Twin } \\
(n=8)\end{array}$ & $\begin{array}{c}\text { Singleton } \\
(n=5)\end{array}$ & $\begin{array}{l}\text { Twin } \\
(n=8)\end{array}$ & $\begin{array}{c}\text { Singleton } \\
(n=5)\end{array}$ \\
\hline$T_{0}$ & $3.20 \pm 0.13^{1}$ & $3.87 \pm 0.34^{1}$ & $39.9 \pm 0.1^{1}$ & $39.7 \pm 0.1^{1}$ & $92 \pm 2^{1}$ & $91 \pm 2^{\mathrm{p}}$ & $194 \pm 4^{\mathrm{a}}$ & $184 \pm 5^{\mathrm{a}}$ \\
\hline$T_{1}$ & $3.34 \pm 0.14^{1}$ & $4.01 \pm 0.35^{1}$ & $39.9 \pm 0.1$ & $39.7 \pm 0.1^{\mathrm{p}}$ & $89 \pm 2^{b}$ & $86 \pm 2^{p}$ & $191 \pm 1^{\mathrm{a}}$ & $182 \pm 2^{b}$ \\
\hline$T_{2}$ & $3.50 \pm 0.18^{\mathrm{a}}$ & $4.17 \pm 0.38^{\mathrm{a}}$ & $39.8 \pm 0.1^{\mathrm{b}}$ & $39.6 \pm 0.1^{\mathrm{b}}$ & $84 \pm 3^{\mathrm{m}}$ & $86 \pm 2^{\mathrm{m}}$ & $188 \pm 2^{b}$ & $180 \pm 4^{b}$ \\
\hline$T_{4}$ & $3.78 \pm 0.21^{\mathrm{a}}$ & $4.44 \pm 0.39^{\mathrm{a}}$ & $39.7 \pm 0.1^{\mathrm{m}}$ & $39.6 \pm 0.1^{\mathrm{b}}$ & $84 \pm 3^{c}$ & $85 \pm 4^{c}$ & $186 \pm 2^{c}$ & $178 \pm 2^{\mathrm{c}}$ \\
\hline$T_{6}$ & $4.06 \pm 0.24^{\mathrm{a}}$ & $4.70 \pm 0.40^{\mathrm{a}}$ & $39.7 \pm 0.1^{\mathrm{m}}$ & $39.6 \pm 0.1^{\mathrm{a}}$ & $82 \pm 4^{\mathrm{i}}$ & $83 \pm 3^{c}$ & $184 \pm 3^{\mathrm{c}}$ & $173 \pm 2^{\mathrm{i}}$ \\
\hline$T_{8}$ & $4.35 \pm 0.27^{\mathrm{a}}$ & $4.97 \pm 0.42^{\mathrm{a}}$ & $39.7 \pm 0.1^{\mathrm{i}}$ & $39.6 \pm 0.1^{\mathrm{a}}$ & $80 \pm 4^{\mathrm{i}}$ & $82 \pm 3^{i}$ & $179 \pm 4^{c}$ & $169 \pm 3^{\mathrm{i}}$ \\
\hline$T_{10}$ & $4.63 \pm 0.30^{\mathrm{a}}$ & $5.24 \pm 0.43^{\mathrm{a}}$ & $39.7 \pm 0.1^{\mathrm{i}}$ & $39.6 \pm 0.1^{\mathrm{a}}$ & $78 \pm 3^{\mathrm{d}}$ & $80 \pm 3^{\mathrm{d}}$ & $177 \pm 2^{\mathrm{d}}$ & $165 \pm 2^{\mathrm{i}}$ \\
\hline$T_{12}$ & $4.91 \pm 0.33^{\mathrm{a}}$ & $5.05 \pm 0.44^{\mathrm{a}}$ & $39.6 \pm 0.1^{\mathrm{n}}$ & $39.5 \pm 0.1^{\mathrm{n}}$ & $77 \pm 4^{\mathrm{d}}$ & $79 \pm 4^{\mathrm{n}}$ & $172 \pm 3^{e}$ & $162 \pm 2^{\mathrm{e}}$ \\
\hline$T_{14}$ & $5.20 \pm 0.36^{\mathrm{a}}$ & $5.77 \pm 0.46^{\mathrm{a}}$ & $39.6 \pm 0.1^{\mathrm{f}}$ & $39.5 \pm 0.1^{\mathrm{e}}$ & $75 \pm 4^{\mathrm{a}}$ & $78 \pm 5^{\mathrm{n}}$ & $169 \pm 2^{f}$ & $161 \pm 5^{\mathrm{f}}$ \\
\hline$T_{16}$ & $5.48 \pm 0.39^{\mathrm{a}}$ & $6.04 \pm 0.47^{\mathrm{a}}$ & $39.6 \pm 0.1^{\mathrm{f}}$ & $39.5 \pm 0.1^{\mathrm{f}}$ & $74 \pm 4^{\mathrm{f}}$ & $75 \pm 3^{f}$ & $167 \pm 4^{\mathrm{g}}$ & $158 \pm 2^{\mathrm{f}}$ \\
\hline$T_{18}$ & $5.77 \pm 0.42^{\mathrm{a}}$ & $6.31 \pm 0.48^{\mathrm{a}}$ & $39.7 \pm 0.1^{\mathrm{f}}$ & $39.5 \pm 0.2^{\mathrm{h}}$ & $73 \pm 5^{f}$ & $74 \pm 3^{g}$ & $166 \pm 3^{\mathrm{h}}$ & $156 \pm 2^{\mathrm{g}}$ \\
\hline$T_{20}$ & $6.05 \pm 0.45^{\mathrm{a}}$ & $6.57 \pm 0.50^{\mathrm{a}}$ & $39.6 \pm 0.1^{\mathrm{o}}$ & $39.5 \pm 0.1^{\circ}$ & $71 \pm 5^{\mathrm{h}}$ & $74 \pm 3^{\mathrm{h}}$ & $163 \pm 3^{\mathrm{h}}$ & $154 \pm 2^{\mathrm{g}}$ \\
\hline$T_{22}$ & $6.33 \pm 0.48^{\mathrm{a}}$ & $6.84 \pm 0.51^{\mathrm{a}}$ & $39.5 \pm 0.1^{\mathrm{j}}$ & $39.4 \pm 0.1^{\circ}$ & $68 \pm 4^{\circ}$ & $72 \pm 3^{\circ}$ & $161 \pm 4^{h}$ & $153 \pm 2^{\mathrm{j}}$ \\
\hline$T_{24}$ & $6.62 \pm 0.51^{\mathrm{a}}$ & $7.11 \pm 0.52^{\mathrm{a}}$ & $39.5 \pm 0.1^{\mathrm{j}}$ & $39.4 \pm 0.1^{\mathrm{o}}$ & $67 \pm 4^{j}$ & $71 \pm 5^{\circ}$ & $160 \pm 3$ & $150 \pm 3^{\mathrm{j}}$ \\
\hline$T_{26}$ & $6.90 \pm 0.54^{\mathrm{a}}$ & $7.37 \pm 0.54^{\mathrm{a}}$ & $39.5 \pm 0.1^{\mathrm{k}}$ & $39.4 \pm 0.1^{\mathrm{k}}$ & $66 \pm 3^{\mathrm{k}}$ & $70 \pm 4^{j}$ & $157 \pm 4$ & $147 \pm 3^{\mathrm{k}}$ \\
\hline$T_{28}$ & $7.18 \pm 0.57^{\mathrm{a}}$ & $7.64 \pm 0.55^{\mathrm{a}}$ & $39.4 \pm 0.1$ & $39.4 \pm 0.1$ & $64 \pm 3^{\mathrm{k}}$ & $68 \pm 3^{k}$ & $155 \pm 4$ & $144 \pm 3$ \\
\hline$T_{30}$ & $7.45 \pm 0.59^{a}$ & $7.88 \pm 0.54^{\mathrm{a}}$ & $39.4 \pm 0.1$ & $39.3 \pm 0.1$ & $63 \pm 2$ & $67 \pm 3$ & $152 \pm 5$ & $143 \pm 4$ \\
\hline
\end{tabular}

Significances (Effect of time $P<0.0001$ ): ${ }^{\text {a }}$ vs. $T_{1}-T_{30} ;{ }^{\mathrm{b}}$ vs. $T_{6}-T_{30} ;{ }^{\mathrm{c}}$ vs. $T_{10}-T_{30} ;{ }^{\mathrm{d}}$ vs. $T_{14}-T_{30}$; ${ }^{\mathrm{e}}$ vs. $T_{18}-T_{30} ;{ }^{\mathrm{f}}$ vs. $T_{20}-T_{30} ;{ }^{\mathrm{g}}$ vs. $T_{22}-T_{30} ;{ }^{\mathrm{h}}$ vs. $T_{24}-T_{30} ;{ }^{\mathrm{i}}$ vs. $T_{12}-T_{30} ;{ }^{\mathrm{j}}$ vs. $T_{28}-T_{30} ;{ }^{\mathrm{k}}$ vs. $T_{30} ;{ }^{\mathrm{l}}$ vs. $T_{2}-T_{30} ;{ }^{\mathrm{m}}$ vs. $T_{8}-T_{30} ;{ }^{\mathrm{n}}$ vs. $T_{16}-T_{30} ;{ }^{\mathrm{o}}$ vs. $T_{26}-T_{30} ;{ }^{\mathrm{P}}$ vs. $T_{4}-T_{30} ;{ }^{\mathrm{q}}$ vs. $T_{28} ;{ }^{\mathrm{r}}$ vs. $T_{10} ;{ }^{\mathrm{s}}$ vs. $T_{14}$.

eral resistance and, since the organism of the newborn is not yet able to vary cardiac output, it compensates the limited systolic volume by increasing the heart rate. The decrease observed in RR values highlights the irregularity of the respiratory activity of the offspring during the postnatal period (Davey et al., 1998; Abu-Shaweesh 2004). With the first breath, three major changes that characterize the respiratory adaptation of mammals at birth (onset of external ventilation, clearing of the fetal pulmonary fluid and establishment of a functional residual capacity) occur. In newborn, respiratory system compliance is low and the resistance is high in the first minutes after birth. During the next few days, the former increases by $80 \%$ and the latter decreases by $20 \%$. Both changes (i.e., the increase in lung compliance and the drop in total pulmonary resistance) mainly reflect the changes in mechanical properties of the lung that come with the progressive clearing of the pulmonary fluid and the expansion of the lungs (Mortola, 2001).

The values of BW, RT, HR and RR showed no effect of twinning $(P>0.05)$ in lambs (Fig. 1), whereas twin kids showed statistically significantly lower BW and higher RT and HR values $(P<0.01)$ compared to singletons at most of the considered data points (Fig. 2).

Both twin lambs and kids showed lower birth BW values compared to singletons and their postnatal growth rates were relatively constant throughout the monitoring period, such that the newborn twins were lighter than singletons until day
30 of life. However, no statistically significant difference in BW values between twin and singleton lambs was observed during the monitoring period, whereas twin kids were statistically lighter than singletons from birth until day 8 of life. This difference could be due to a greater degree of intrauterine growth restriction in twin kids with respect to twin lambs, possibly because of species differences (De Matteo et al., 2008). It was demonstrated that twins are growth restricted in utero compared with singletons because of the reduced placental oxygen and nutrient availability (Aleksiev, 2009). Although an increase in litter size is known to be associated with an increase in placental weight and exchange surface area of cotyledons (Kaulfuss et al., 2000), this compensatory mechanism is insufficient to meet all fetal requirements and the surface area of cotyledons for each lamb decrease with increased litter size (Dwyer, 2003). The growth restriction in utero likely to occur in twins (De Matteo et al., 2008) could also explain the statistically significant effect of twinning on HR values observed in kids at birth and at most of the other considered data points. In particular, twin kids showed higher HR values with respect to singletons suggesting an altered nutritional or fluid homeostatic status of twins (De Matteo et al., 2008) that is probably the result of the small size of the heart of twins compared to that of singletons. Effectively, catch-up growth likely to occur in twins during intrauterine life has significant implications for later health, as organs that have terminally developed in proportion to body size in utero 

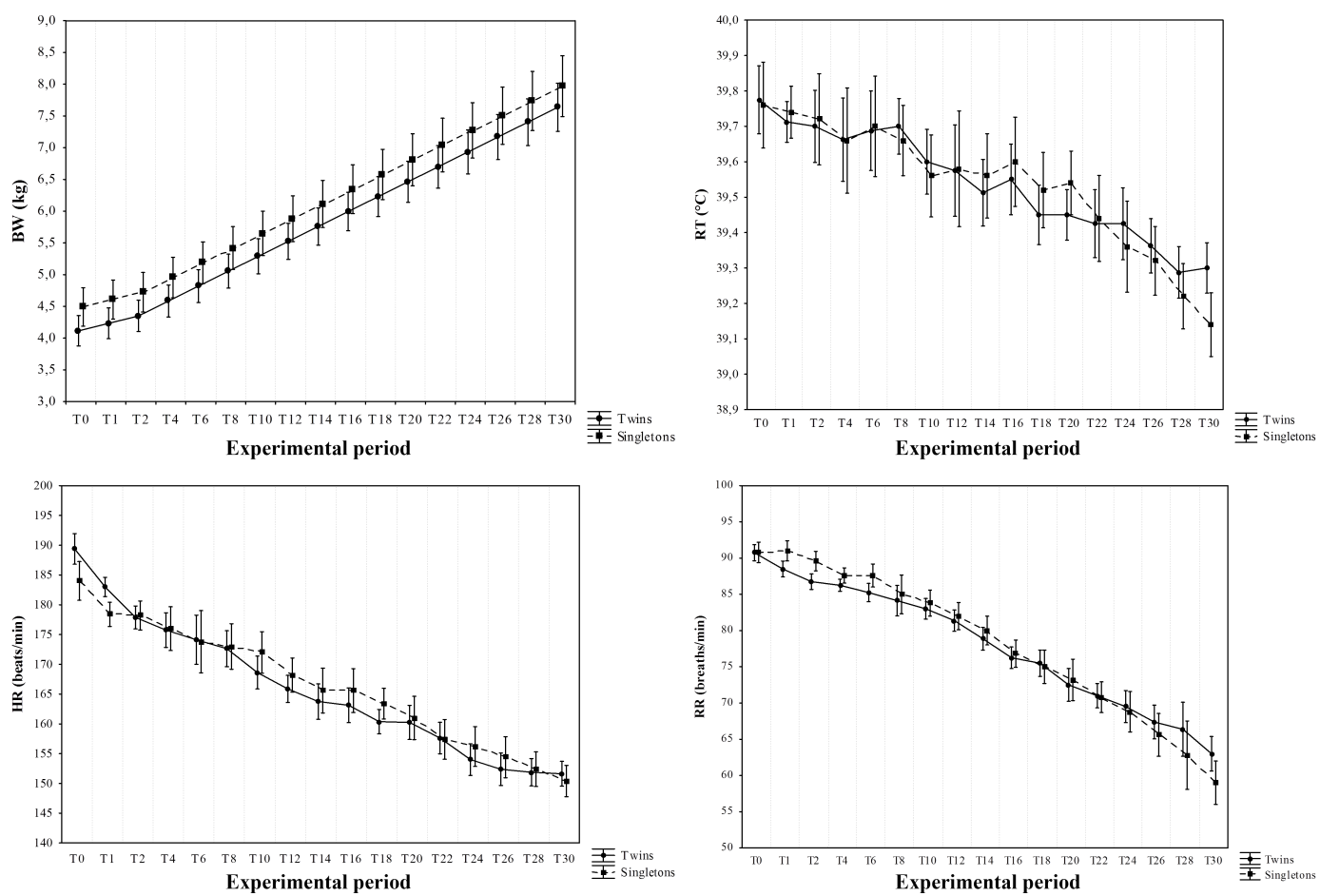

Figure 1. Mean values of body weight (BW), rectal temperature (RT), heart rate (HR) and respiratory rate (RR) obtained from singleton and twin lambs during the first month of life. Vertical bars denote $\pm 95 \%$ confidence intervals.
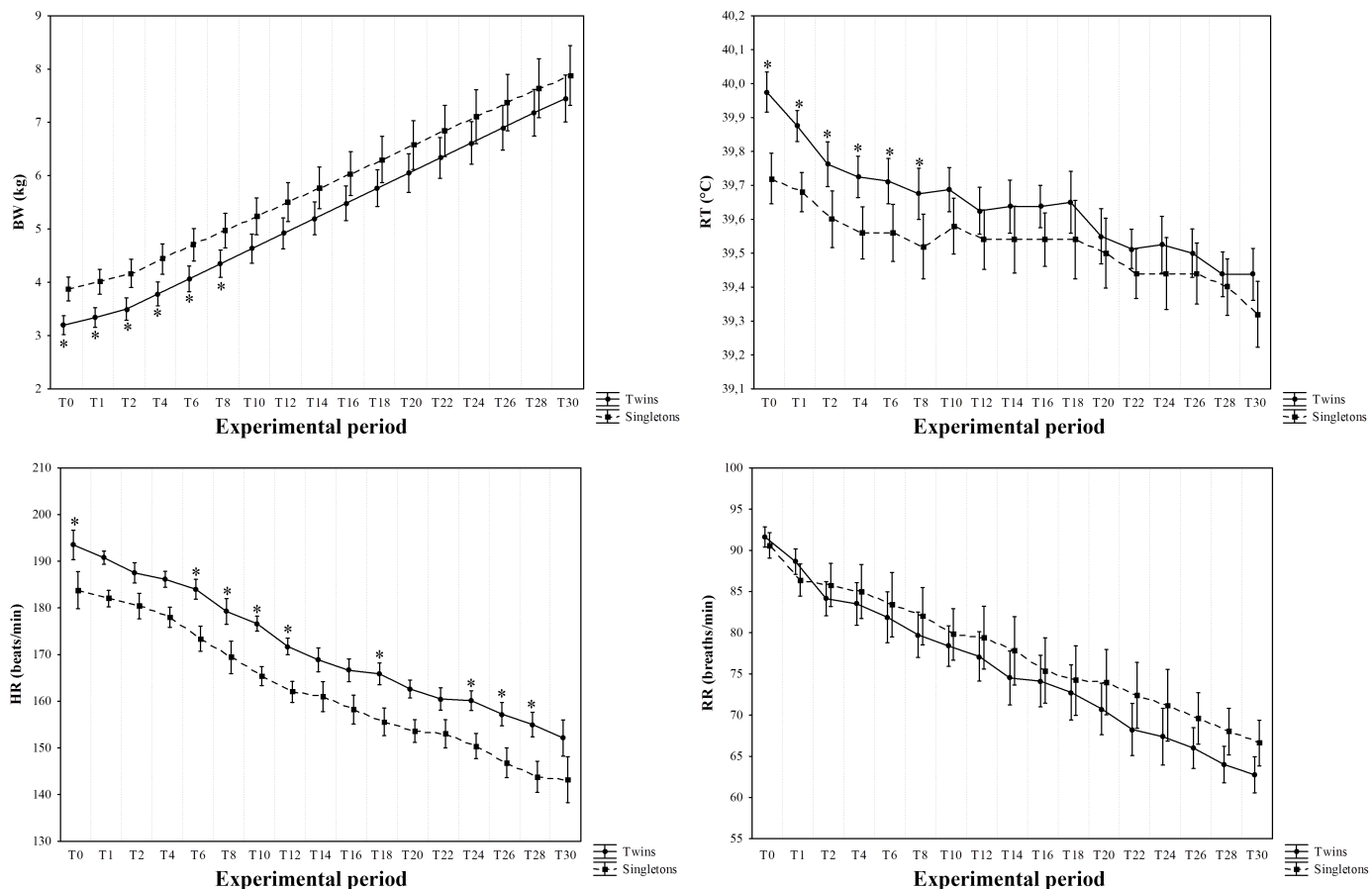

Significances: *vs Singletons $(P<0.01)$

Figure 2. Mean values of body weight (BW), rectal temperature (RT), heart rate (HR) and respiratory rate (RR) obtained from singleton and twin kids during the first month of life. Vertical bars denote $\pm 95 \%$ confidence intervals. 
may be reduced in size or complexity relative to body size after catch-up growth (Mitchel et al., 2004; De Matteo et al., 2008). The RT values measured in twin kids were statistically higher than in singleton kids during the first week of life. This difference might indicate a different degree of physiological maturation of homoeothermic mechanisms in singleton and twin kids at birth and of their ability to activate heat-producing and/or heat-preserving mechanisms, which ultimately influence body heat (Aleksiev, 2009). Twin kids showed a more marked decrease in RT within $24 \mathrm{~h}$ after birth with respect to singletons. This suggests that twins cooled to a greater extent than singletons, which may partly reflect the effect of body weight (Aleksiev, 2009). It has been stated that light newborns have a greater surface area to body mass ratio, which results in an increased body heat loss to the environment (Stafford et al., 2007). The heavier singletons had lower RT values after delivery compared to the lighter twins. It could be assumed that singletons made use of shivering thermogenesis to a lesser extent than the twins with lower birth weight and there may also be insufficient cold stimuli to cause a metabolic overreaction and RT increase.

\section{Conclusions}

Under the conditions of this study, despite the observed changes, all newborn kids and lambs exhibited good homeostatic ability and were able to maintain the assessed parameters within the physiological limits. The results obtained in this study make a contribution to the knowledge of homeostatic, cardiorespiratory and thermoregulatory adaptations occurring both in singleton and in twin lambs and kids during the first 30 days of life. Moreover, our findings indicate that the BW, RT, HR and RR values, whose homeostasis is still evolving in newborn, should be interpreted dynamically as a function of the period of postnatal adaptation and also of the type of birth.

Further aspects of homeostatic, cardiorespiratory and thermoregulatory adaptations in a greater number of twin and single-born lambs and kids are worth exploring.

Author contributions. All authors have made substantial contributions to each step of the experimental procedure and manuscript preparation. In particular, Francesco Fazio designed the experiment and performed the sampling, Francesca Arfuso performed the laboratory analysis and Claudia Giannetto analyzed the data. Francesca Arfuso and Elisabetta Giudice prepared the paper. Giuseppe Piccione supervised all stages of the experimental study.

Edited by: S. Maak

Reviewed by: V. Nagyova and two anonymous referees

\section{References}

Abu-Shaweesh, J. M.: Maturation of respiratory reflex responses in the fetus and neonate, Semin. Neonatol., 9, 169-180, 2004.

Aleksiev, Y.: Rectal temperature dynamic in Bulgarian white kids during the first day of postnatal life, Bulg. J. Agric. Sci., 15, 177182, 2009.

Al-Tamimi, H. J.: Thermoregulatory response of goat kids subjected to heat stress, Small Ruminant Res., 71, 280-285, 2007.

Baird, J., Osmond, C., MacGregor, A., Snieder, H., Hales, C. N., and Phillips, D. I.: Testing the fetal origins hypothesis in twins: the Birmingham twin study, Diabetologia, 44, 33-39, 2001.

Chniter, M., Hammadi, M., Khorchani, T., Ben Sassi, M., Ben Hamouda, M., and Nowak, R.: Aspects of neonatal physiology have an influence on lambs' early growth and survival in prolific D'man sheep, Small Ruminant Res., 111, 162-170, 2013.

Davey, M. G., Johns, D. P., and Harding, R.: Postnatal development of respiratory function in lambs studied serially between birth and 8 weeks, Respir. Physiol., 113, 83-93, 1998.

de Geus, E. J., Posthuma, D., Ijzerman, R. G., and Boomsma, D. I.: Comparing blood pressure of twins and their singleton siblings: being a twin does not affect adult blood pressure, Twin Res., 4, 385-391, 2001.

De Matteo, R., Stacy, V., Probyn, H. M., Desai, M., Ross, M., and Harding, R.: The perinatal development of arterial pressure in sheep: effects of low birth weight due to twinning, Reprod. Sci., 15, 66-74, 2008.

Dwyer, C. M.: Behaviour development in the neonatal lamb: effect of maternal and birth-related factors, Theriogenology, 59, 10271050, 2003.

Dwyer, C. M., Calvert, S. K., Farish, M., Donbavand, J., and Pickup, H. E.: Breed, litter and parity effects on placental weight and placentome number, and consequences for the neonatal behaviour of the lamb, Theriogenology, 63, 1092-1110, 2005.

Dwyer, T., Blizzard, L., Morley, R., and Ponsonby, A. L.: Within pair association between birth weight and blood pressure at age 8 in twins from a cohort study, Br. Med. J., 319, 1325-1329, 1999.

Hemingway, A. and Hemingway, C.: Respiration of sheep at thermoneutral temperatures, Resp. Physiol., 1, 30-37, 1966.

Kaulfuss, K. H., Schramm, D., and Berttram, M.: Effects of genotype, dams age, litter size, birth weight and ram on morphological parameters of the placenta in sheep, Deut. Tierarztl. Woch., 107, 269-275, 2000.

Miller, W. C. and West, G. P.: Black's Veterinary Dictionary, Adam and Charles Black, London, UK, 1972.

Mir, S. A., Nazki, A. R., and Raina, R.: Comparative electrocardiographic studies, and differing effects of pentazocine on ECG, heart and respiratory rates in young sheep and goats, Small Ruminant Res., 37, 13-17, 2000.

Mitchell, E. K., Louey, S., Cock, M. L., Harding, R., and Black, M. J.: Nephron endowment and filtration surface area in the kidney after growth restriction of fetal sheep, Pediatr. Res., 55, 769-773, 2004.

Morris, S. T. and Kenyon, P. R.: The effect of litter size and sward height on ewe and lamb performance, New Zeal. J. Agr. Res., 47, 275-286, 2004. 
Mortola, J. P.: Respiratory Physiology of Newborn Mammals: A Comparative Perspective, The Johns Hopkins University Press, Baltimore and London, UK, 2001.

Nowak, R. and Poindron, P.: From birth to colostrum: early steps leading to lamb survival. Reprod. Nutr. Dev., 46, 431-446, 2006.

Ocak, S., Onder, H., and Guney, O.: Thermo-physiological responses and some growth parameters in kids during the first 45 days under Mediterranean climatic conditions in Turkey, J. Anim. Vet. Adv., 8, 1237-1241, 2009.

Piccione, G., Borruso, M., Fazio, F., Giannetto, C., and Caola, G.: Physiological parameters in lambs during the first 30 days postpartum, Small Ruminant Res., 72, 57-60, 2007.

Piccione, G., Bertolucci, C., Giannetto, C., and Giudice, E.: Clotting profile in newborn maltese kids during the first week of life, J. Vet. Diagn. Invest., 20, 114-118, 2008.

Piccione, G., Casella, S., Giannetto, C., Vazzana, I., Niutta, P. P., and Giudice, E.: Influence of age on serum proteins in the calf, Acta Vet.-Beograd, 59, 413-422, 2009.

Piccione, G., Casella, S., Pennini, P., Giannetto, C., Costa, A., and Caola, G.: Monitoring of physiological and blood parameters during perinatal and neonatal period in calves, Arq. Bras. Med. Vet. Zootec., 62, 1-12, 2010.
Piccione, G., Arfuso, F., Monteverde, V., Vazzana, I., Zumbo, A., and Faggio, C.: Monitoring of some metabolic parameters in comisana lambs during the neonatal period, Large Anim. Rev., 19, 133-137, 2013.

Plush, K. J., Brien, F. D., Hebart, M. L., and Hynd, P. I.: Thermogenesis and physiological maturity in neonatal lambs: a unifying concept in lamb survival, Anim. Prod. Sci., 56, 736-745, 2016.

Plush, K. J., Hebart, M. L., Brien, F. D., and Hynd, P. I.: Variation in physiological profiles may explain breed differences in neonatal lamb thermoregulation, Anim. Prod. Sci., 56, 746-756, 2015.

Poulter, N. R., Chang, C. L., MacGregor, A. J., Snieder, H., and Spector, T. D.: Association between birth weight and adult blood pressure in twins: historical cohort study, Br. Med. J., 319, 13301333, 1999.

Stafford, K. J., Kenyon, O. R., Morris, S. T., and West, D. M.: The physical state and metabolic status of lambs of different birth rank soon after birth, Livest. Sci., 111, 10-15, 2007.

Vannucchi, C. I., Rodrigues, J. A., Silva, L. C. G., Lúcio, C. F., and Veiga, G. A. L.: A clinical and hemogasometric survey of neonatal lambs, Small Ruminant Res., 108, 107-112, 2012. 